\title{
Determining the Technical Efficiency of Hospitals in Tabriz City Using Data Envelopment Analysis for 2013-2014
}

\author{
Fereshteh Farzianpour ${ }^{1}$, Amir Hossein Emami ${ }^{2}$, Abbas Rahimi Foroushani ${ }^{3} \&$ Akbar Ghiasi ${ }^{4}$ \\ ${ }^{1}$ Department of Health Management and Economics, School of Public Health, Tehran University of Medical \\ Sciences, Tehran, Iran \\ ${ }^{2}$ Department of Internal Medicine, School of Medicine, Tehran University of Medical Sciences, Tehran, Iran \\ ${ }^{3}$ Departments of Epidemiology and Biostatistics, Tehran University of Medical Sciences, Tehran, Iran \\ ${ }^{4}$ Department of Health Management, Public Health School, Zabol University of Medical Sciences, Zabol, Iran \\ Correspondence: Fereshteh Farzianpour, Department of Health Management and Economics, School of Public \\ Health, Tehran University of Medical Sciences, Tehran, Iran. E-mail: farzianp@sina.tums.ac.ir
}

Received: November 17, 2015 Accepted: July 15, 2016 Online Published: September 13, 2016

doi:10.5539/gjhs.v9n5p42

URL: http://dx.doi.org/10.5539/gjhs.v9n5p42

\begin{abstract}
Background and Objectives: This study was conducted to evaluate the technical efficiency of hospitals (training and non-training hospitals of Tabriz city) affiliated with the Medical Science University, based on performance indicators and mathematical model of data envelopment analysis (DEA) in 2014.
\end{abstract}

Methods: The present research is a cross sectional study conducted to assess the scale, technical and managerial efficiency of hospitals from 2013 to2014. Then, a comparison of the collected data was made among the hospitals under study. The model of minimization of production factors and variable return was used in analyzing the data.

Results: The collected information included two input groups which consisted of the number of physicians (general physicians and specialists), total personnel and active beds, and output groups which consisted of the number of out-patients and bed occupancy rate. Then, the technical, scale and managerial efficiency of the hospitals were calculated and the efficient (Performance Coefficient of $E=1$ ) and inefficient (below 1) hospitals were obtained. The average technical, scale and managerial efficiencies in both 2013 and 2014 was equal to 0.817 , 0.956 and 0.856 , respectively.

Conclusion: Hospitals having lower efficiency can model efficient reference hospitals, so as to increase their performance and also approach the efficiency border by better management of human and financial resources.

Keywords: hospital, data envelopment analysis, technical efficiency.

\section{Introduction}

Hospitals are known as the largest and most costly functioning units of the health care system. Thus, a careful consideration of their performance and cost efficiency is of particular significance. This study intends to evaluate the efficiency of hospitals affiliated with Tabriz University of Medical Sciences, using the data envelopment analysis (DEA) method.There has been an increase in the cost of hospital services in most countries over the years (Nikoukar et al., 2011), such that approximately $60 \%$ of the total health sector costs are dedicated to hospitals (Farzianpour et al., 2011). The rapid growth of treatment costs compared to the incomes in developing countries, economic crises and shortage of government funding in these countries, have made hospitals to encounter many problems and suffer heavy pressure in trying to control and reduce the costs (Gagliardi et al.,2010). In most developing countries, about $5 \%$ of GDP and $10.5 \%$ of government spending is dedicated to the health sector. But today in many of these countries, the health sector is faced with strong constraints in resources (Mohammad Pour et al., 2011).

Despite the high costs spent on hospitals, there still exists great difference between the growth of available resources and the required resources in this sector, and as such it seems that due to the economic infrastructure and their severe vulnerability in the face of fluctuations of currency and commodity markets, these problems will also be doubled. In addition, despite the increasing demand for health and treatment goods and services, hospitals are faced with limited resources, so that complete response to the needs of consumers in this sector seems virtually out 
of reach. This is why hospitals, which serve as the main organizations for the provision of health care, are of great importance and sensitivity (Farzianpour et al., 2010, 2011). The major problems associated with these organizations include, competing with their counterparts and dealing with crises such as increase in pressure coming from the government, insurance companies and patients to reduce costs and increase the quality of medical services, lack of efficiency in the health sector and the inefficient use of good management techniques to optimize the use of resources. Therefore, the necessity of improving efficiency in these organizations according to Peter Drucker is the only determinant of victory or defeat in the competition with others, and it should be considered (Farzianpour et al., 2010, 2011). In this context, economists and policy makers have introduced efficiency as an important measure for organizing and allocating resources to health care services (Mohammad Pour et al., 2008). Since healthcare is one of the basic needs of any society, and attention to health care and investment in this area increases work force productivity and production, therefore the allocation of adequate resources and appropriate use of resources in this sector is of great importance. Considering this, the necessity of using a method to determine the optimal amount of resources and its appropriate use with more efficiency is of great importance (Farzianpour et al., 2011). Although the main asset of the health care system, both financial and human resources are spent in hospitals, few studies have been conducted on the costs and hospital resources before 1980, but from 1986 onwards, several studies have been conducted on the same subject. The conducted studies indicated extensive losses in this sector. According to the estimation of the World Health Organization, about $40 \%$ of the resources available to the health sector is wasted in Latin America, and this is the reason why these resources which are important due to their sizes and type of hospital operations, can be maintained by improving the efficiency. For example, a study done in Malawi showed that the correction of inefficient operational management led to about $40 \%$ savings of non-personnel costs of hospital (Farzianpour et al., 2013).

Therefore, proper cost management in hospitals as an economic enterprise and the need for optimal use of facilities and resources is bound to the application of economic analysis (Farzianpour et al., 2011; Abbasi et al., 2012).

One of economic analysis and tools is efficiency measurement. In the absence of efficiency measurement, decision making can be very difficult for policy makers and planners, and decisions which are finally selected are rather unscientific and impractical in most cases and result in waste of valuable resources in the health sector. There is no doubt that determining efficiency in hospitals in production, allocation and consumption of resources, and productivity in the health sector is one of the basic steps that should be taken rapidly in this field.

In this regard, bed occupancy rate, bed turnover rates, and average length of stay are known as the most important indicators of hospital performance. However, other indicators are used in order to estimate the efficiency and investigate the performance of hospitals. Since some hospital parameters in the study country are unsatisfactory and in some cases there exist a big difference with the desired status, which implies a huge waste of national resources, the importance of studies to evaluate the efficiency of hospitals seems absolutely necessary. This is why according to the estimate of the Plan and Budget Organization in the current situation, every hospital bed takes an average of 250 million dollars cost to reach the actual use stage. Three hundred (300) million dollars of funds are wasted annually on passive hospital beds, and thiscan be termed as inefficient and inappropriate use of resources and lack of management (Abbasi et al., 2012; Bakhateiyari et al., 2015). Although the efficiency of the studied hospitals showed a favorable level, a slight efficiency improvement is required, meaning that the managers are still expected to provide the necessary planning towards increasing the efficiency. For this purpose, in the study, a mathematical efficiency measurement method called data envelopment analysis (DEA) was used to determine how much reduction in costs (inputs) can still create the same amount of output (Bakhateiyari et al., 2015; Farzianpour et al., 2014; Barnum et al., 2009; Nikoukar et al., 2011). Technical efficiency is defined as the ratio of personnel output to input.It deals with a combination of data which produce certain output. Concerning this type of efficiency, the main question to be asked is if the highest degree of output is obtained considering each personnel output to input (Tlotlego et al., 2010).

\subsection{Literature Review}

$$
\text { Technical efficiency }=\frac{\text { Output }}{\text { Input }}
$$

Hospitals are the main consumer of resources in any health sector thus; Improvement of their efficiency is the main way to decrease the hospital costs. Thus, providing criteria for evaluation of hospital performance and productivity is important. These features are doubled, especially in developing countries, considering their economic structure and extreme vulnerability to deal with fluctuations in currency and commodity markets. In a way, that full response to the needs of consumers in this sector, even in the most advanced countries, seems to be out of reach .Hence, the Iranian hospitals are no exception from this issue. In this situation, the hospitals managers' strategies for reducing the costs and Increasing the productivity is necessary. 
Several techniques to assessment hospital efficiency and productivity are usually considered either parametric or nonparametric. Nonparametric method such as data envelopment analysis are the most popular (Farzianpour et al., 2011).

Data Envelopment Analysis (DEA): DEA is an excellent way to determine thedegree of efficiency of the decision making units (DMU). DEA was offered by Charnes et al. (1978) (Figures 1 and 2). In this method, the deficiency of the decision making units are calculated using mathematical models. Some inputs and outputs are defined for the DMUs, and for each DMU the output and input are calculated. Then, DEA models determine the study frontier by providing a comparison between the DMUs. Each DMU which lies on the frontier is recognized as an efficient DMU while DMUs which lie below the frontier are recognized as inefficient and the degree of their inefficiency is calculated based on their distance to the frontier (Cook \& Zhu, 2008). DEA calculates the ability of the management to optimally use existing possibilities as the efficiency score. In this method, units which use the most capacity of their resources are known as efficient units and all other units are evaluated in comparison with this unit (Afzali et al., 2009). In this technique, first the input and output indices which show the resources used and products or services of the unit are identified and calculated, then suitable DEA is used to calculate the efficiency of the units. One major feature of this technique is that after evaluating the efficiency of the decision making units, it offers corrections and improvements specific to each, and in case of achieving optimal level of inputs and outputs, the unit reaches optimal state. Since there are different conditions in considering the production atmosphere of the organizations, various DEA models have been developed and each is used in a specific condition. All models are used to evaluate the efficiency of DMUs. The CCR model is basic to many other models which can be formed from CCR through suitable changes. The models are designed based on principles stated in the DEA theory (Charnes et al., 1987):

(A1Minimise )

Equation( $E_{\mathrm{n}}$ )

$W_{i}, \ldots w_{n}, S_{n}$

Subject to:

$$
\begin{gathered}
\sum_{j=i}^{N} W_{j} Y_{i j}-Y_{i n} \geq \mathrm{i}=1, \ldots, \mathrm{I} \\
\sum_{j=i}^{N} W_{j} Y_{k j}-E_{n} Y_{k n} \geq \mathrm{K}=1, \ldots, \mathrm{K} \\
W_{j} \geq \mathrm{j}=1, \ldots, \mathrm{N}
\end{gathered}
$$

$\mathrm{N}=$ The number of firms in the sample

I: Number of outputs

$\mathrm{K}$ : Number of inputs

$\mathrm{Wj}$ : Weight used in the business

$E_{n}: N$ technical efficiency of firms

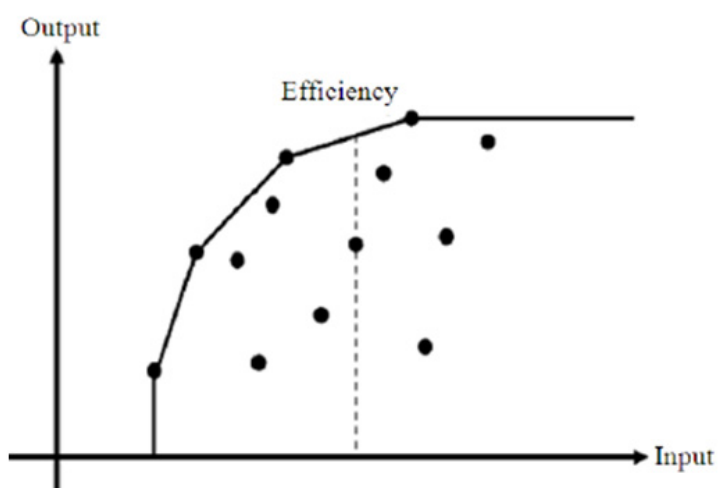

Figure 1. (Chang et al., 2011)

\section{Research Method}

The present research is a cross sectional study used to assess the scale, technical and managerial efficiency in 
health centers and 23 hospitals affiliated to Tabriz University of Medical Sciences, using the DEA mathematical model during the years 2013-2014. Then, a comparison of the collected data was made among the hospitals under study.

Since the findings and results of this study can be used by the authorities of the hospitals under study and generally by policymakers in the health sector, it is an applied research. This study was approved by the Department of Education and Tehran University of Medical Sciences Ethics Committee No. 28516 on 03.15.2015. In this research, no sampling was done. However, due to lack of cooperation from 21 to 24 hospitals, the data were collected from only 19 hospitals and analyzed.

In the present study, data was collected using a questionnaire which contained the profile of the hospital and required variables (inputs including: the number of specialist and general physician, all other staff and active beds and outputs including: bed occupancy rate, and the number of outpatient reception) to be analyzed. Then, an attempt was made by the researchers to complete the questionnaire. The number of questionnaires related to each hospital was same as the number of years of investigation. From the data extracted from the forms in each year, the technical, scale and managerial efficiencies were obtained using data envelopment analysis (DEA). This system of analysis allowed for the simultaneous investigation of several data and output by different measurement units. Considering this feature, this method is quite appropriate for several multi product organizations like hospitals. In addition, by using this method of research, production factors in decision-making units (organizations studied that are hospitals in this research) can also be identified. This is a management method that generally by combining all the units under study, makes a virtual unit with the highest efficiency and assesses inefficient units associated with them (Mohammad Pour et al., 2008; Abbasi et al., 2012). Thus, in this study, by using data envelopment analysis, the technical, scale and management efficiency of all hospitals in Tabriz was estimated through minimization of production factors, using cross-sectional data and assuming variable returns to scale (VRS). The following linear programming model was used to carry this out. In this model, $\mathrm{N}$ represents the number of firms in the sample, and I and $\mathrm{K}$, respectively are the number of outputs and inputs, $W_{j}$ is the weight used in the $\mathrm{N}$ firms which is in fact a N*1 firms of fixed values that shows the weights of the reference set. $S_{n}$ shows the technical efficiency of the Nth firm. $Y_{i j}$ and $X_{k j}$, respectively show the ith output values and kth input of firm i.

One of the main reason for choosing this model is that in hospitals, output (number of patients) are not in the control hospitals; hence the model of maximization of output cannot be used to assess the technical efficiency of the hospital. Hospitals which have obtained grade 1 in every type of efficacy are identified as efficient and for any rate of distance from 1, it is expected that their inputs should be decreased in order to achieve maximum efficiency.

It should be noted that the inputs used to estimate the scale, technical and managerial efficiency, by using data envelopment analysis, included the number of physicians, nurses, other staff and active beds. Outputs used included bed occupancy rate and the number of outpatient reception.

Since the efficiency measurement in this study was based on input and output assumption, therefore the additional inputs and outputs were specified using this method, which indicated the amount of input and output by a reduction or increase through which hospital managers can achieve maximum efficiency.

\subsection{Data Analysis}

The data was first entered into Excel software, then the necessary steps to filter data were taken and finally data of all hospitals were entered in WIN DEAP software with division of each year. Finally, the technical, managerial and scale efficiency were determined.

\section{Results}

Table 1 shows the number of inputs and outputs of the hospitals in the city of Tabriz in 2013 by division of hospitals under study. From the table, hospital 1 had the highest number of hospital beds and hospital 17 had the lowest number of beds. 
Table 1. Input and output parameters for hospitals in the city of Tabriz in 2013

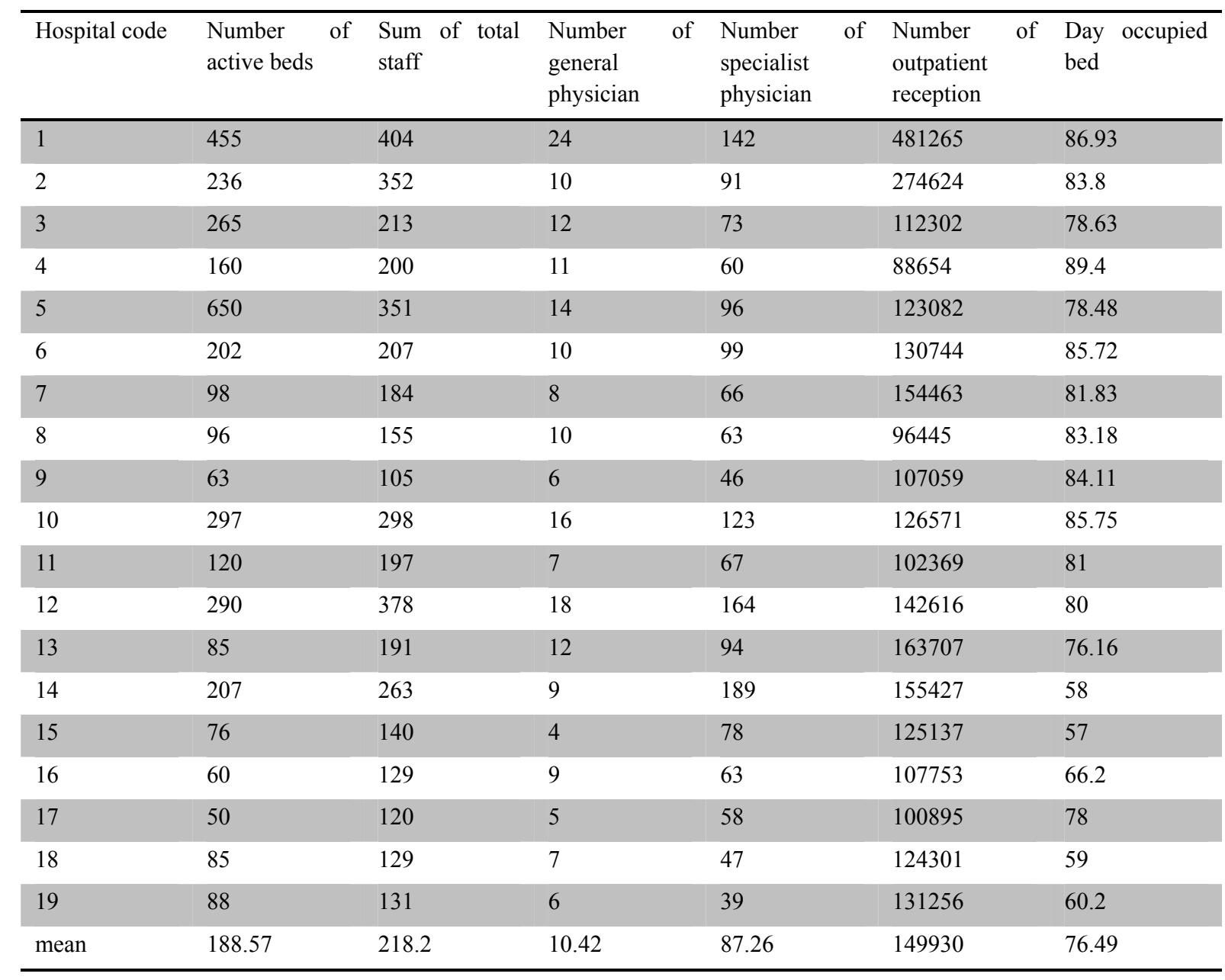

Table 2 presents input and output hospitals in the city of Tabriz in 2014 by division of hospitals studied. From the table, hospital 12 had the highest number of physicians while hospital 17 had the minimum number of specialists.

Table 2. Input and output parameters of the city of Tabriz hospitals in 2014

\begin{tabular}{llllllllll}
\hline Hospital code & $\begin{array}{l}\text { Number } \\
\text { active beds }\end{array}$ & of & $\begin{array}{l}\text { Sum of total } \\
\text { staff }\end{array}$ & $\begin{array}{l}\text { Number } \\
\text { general } \\
\text { physician }\end{array}$ & $\begin{array}{l}\text { of } \\
\text { specialist } \\
\text { physician }\end{array}$ & $\begin{array}{l}\text { Number } \\
\text { outpatient } \\
\text { reception }\end{array}$ & $\begin{array}{l}\text { Day occupied } \\
\text { bed }\end{array}$ \\
\hline 1 & 455 & 426 & 29 & 154 & 493670 & 88.35 \\
\hline 2 & 236 & 371 & 14 & 98 & 277301 & 82.54 \\
\hline 3 & 265 & 219 & 17 & 76 & 114923 & 81 \\
\hline 4 & 160 & 216 & 13 & 60 & 90537 & 83.41 \\
\hline 5 & 650 & 374 & 14 & 96 & 126438 & 77 \\
\hline 6 & 202 & 219 & 10 & 104 & 133200 & 86.5 \\
\hline 7 & 98 & 198 & 8 & 68 & 159284 & 84.2 \\
\hline 9 & 96 & 164 & 11 & 63 & 100432 & 79.56 \\
\hline 10 & 63 & 114 & 9 & 51 & 109456 & 86.3 \\
\hline
\end{tabular}




\begin{tabular}{llllllll}
\hline 12 & 290 & 389 & 18 & 165 & 140029 & 77.5 & 74 \\
13 & 85 & 213 & 14 & 94 & 161254 & 54.5 & 53.8 \\
14 & 207 & 270 & 11 & 198 & 151973 & 122875 & 61.64 \\
15 & 80 & 138 & 4 & 81 & 103986 & 72 & 55.13 \\
16 & 60 & 129 & 8 & 63 & 67251 & 122926 & 57.64 \\
17 & 50 & 128 & 6 & 49 & 129854 & 75.14 \\
\hline 18 & 85 & 135 & 7 & 6 & 150746 & 75 \\
\hline mean & 90 & 131 & 12 & 91 & & & 75 \\
\hline
\end{tabular}

Table 3. Ranking training health centers and hospitals affiliated to the Tehran University of Medical Sciences based on technical efficiency using DEA model based on inputs

\begin{tabular}{|c|c|c|c|c|c|c|}
\hline \multirow{2}{*}{$\begin{array}{l}\text { Number } \\
\text { hospital }\end{array}$} & \multirow[t]{2}{*}{ The year 2013} & \multirow[t]{2}{*}{ The year 2014} & \multirow{2}{*}{$\begin{array}{l}\text { efficiency } \\
\text { changes }\end{array}$} & \multirow[t]{2}{*}{ Mean } & \multicolumn{2}{|c|}{ Reference hospital } \\
\hline & & & & & 2013 & 2014 \\
\hline 1 & 1 & 1 & 0 & 1 & 1 & 1 \\
\hline 2 & 1 & 0.962 & 0.038 & 0.981 & 2 & 2 \\
\hline 3 & 0.607392 & 0.661674 & -0.054282 & 0.634533 & 9.19 & $9,19,1$ \\
\hline 4 & 0.815 & 0.82152 & -0.00652 & 0.81826 & 4 & 9,19 \\
\hline 5 & 0.473841 & 0.558441 & -0.0846 & 0.516141 & $19,1,9$ & $19,7,17,9$ \\
\hline 6 & 0.638704 & 0.746 & -0.107296 & 0.692352 & $2,4,9,1$ & 6 \\
\hline 7 & 0.949 & 1 & -0.051 & 0.9745 & 7 & 7 \\
\hline 8 & 0.72237 & 0.751752 & -0.029382 & 0.737061 & 19,9 & 9,19 \\
\hline 9 & 1 & 1 & 0 & 1 & 9 & 9 \\
\hline 10 & 0.41712 & 0.541 & -0.12388 & 0.47906 & $19,2,4,1$ & 10 \\
\hline 11 & 0.782432 & 0.86912 & -0.086688 & 0.825776 & 17,9 & $9,7,17$ \\
\hline 12 & 0.37576 & 0.403788 & -0.028028 & 0.389774 & $1,2,15,9$ & $15,9,1,7$ \\
\hline 13 & 0.987 & 1 & -0.013 & 0.9935 & 13 & 13 \\
\hline 14 & 0.623238 & 0.580836 & 0.042402 & 0.602037 & 2,15 & $1,19,15$ \\
\hline 15 & 1 & 1 & 0 & 1 & 15 & 15 \\
\hline 16 & 0.946104 & 0.947 & -0.000896 & 0.946552 & $13,17,9$ & $9,13,17$ \\
\hline 17 & 1 & 1 & 0 & 1 & 17 & 17 \\
\hline 18 & 0.940116 & 0.954304 & -0.014188 & 0.94721 & $1,19,9,13$ & $9,19,17$ \\
\hline 19 & 1 & 1 & 0 & 1 & 19 & 19 \\
\hline
\end{tabular}

As is seen in Table 3, in 2013, the six hospitals 1,2,9,15, 17 and 19 were equal to the efficiency grade of 1 (31\%). Seven hospitals were effective in $2014(36.84 \%)$, but with the difference that the efficiency grade of hospital decreased, while hospitals 13 and 7 were more efficient. Among the 19 hospitals surveyed, 12 hospitals had a decline in efficiency (64\%), such that the highest negative changes were related to hospitals 6 and 10 with values 0.12388 and 0.107296 , respectively. Five hospitals (26\%) experienced no change in efficiency grade over two years. Hospitals 2 and 14 had positive changes over the past two years (10\%). Finally, in this table, reference hospitals (hospital that is determined by the software to be a model for other hospitals virtually) were the hospitals that had a positive change or no change at all. However, hospitals with negative changes had at least one reference hospital. 
Table 4. Ranking health centers and hospitals affiliated to Tabriz University of Medical Sciences based on scale efficiency using data envelopment analysis model based on inputs

\begin{tabular}{|c|c|c|c|c|c|c|}
\hline Number of hospital & The year 2013 & $\begin{array}{l}\text { Return to } \\
\text { scale }\end{array}$ & $\begin{array}{l}\text { The year } \\
2014 \text {. }\end{array}$ & $\begin{array}{l}\text { Return to } \\
\text { scale }\end{array}$ & $\begin{array}{l}\text { Changes of } \\
\text { efficiency over } \\
\text { two years }\end{array}$ & $\begin{array}{l}\text { Mean of two } \\
\text { years }\end{array}$ \\
\hline 1 & 1 & - & 1 & - & 0 & 1 \\
\hline 2 & 1 & - & 0.962 & Descending & 0.038 & 0.981 \\
\hline 3 & 0.999 & - & 0.998 & Descending & 0.001 & 0.998 \\
\hline 4 & 0.815 & Descending & 0.978 & Ascending & -0.163 & 0.896 \\
\hline 5 & 0.969 & Descending & 0.999 & Ascending & -0.03 & 0.984 \\
\hline 6 & 0.764 & Descending & 0.746 & Descending & 0.018 & 0.755 \\
\hline 7 & 0.949 & Descending & 1 & - & -0.051 & 0.9745 \\
\hline 8 & 0.995 & Ascending & 0.954 & Ascending & 0.041 & 0.9745 \\
\hline 9 & 1 & - & 1 & - & 0 & 1 \\
\hline 10 & 0.790 & Descending & 0.541 & Descending & 0.249 & 0.6655 \\
\hline 11 & 0.998 & Descending & 0.970 & Descending - & 0.028 & 0.984 \\
\hline 12 & 0.976 & Descending & 0.966 & Descending & 0.01 & 0.971 \\
\hline 13 & 0.987 & Descending & 1 & - & -0.013 & 0.9935 \\
\hline 14 & 0.994 & Descending & 0.998 & Ascending & -0.004 & 0.996 \\
\hline 15 & 1 & - & 1 & - & 0 & 1 \\
\hline 16 & 0.998 & Descending & 1 & - & -0.002 & 0.999 \\
\hline 17 & 1 & - & 1 & - & 0 & 1 \\
\hline 18 & 0.998 & Descending & 0.992 & Ascending & 0.006 & 0.995 \\
\hline 19 & 1 & - & 1 & - & 0 & 1 \\
\hline
\end{tabular}

Table 4 indicates the scale efficiency of the hospitals under study. As shown in the table, in 2013 six hospitals 1, 2, $9,15,17$ and 19 had an efficiency grade equal to 1 .

But in 2014, eight hospitals had scale efficiency grade 1, with the difference that hospitals 7, 13 and 16 had efficiency grade 1 and hospital 2 had grade less than 1 . The next thing is related to the indicator of the scale return efficiency (Returns to scale is related to manner of changes according to identical and appropriate changes of all production factors). In increasing return to scale, with the doubling of production factors, production increased more than double. In diminishing returns to scale, production was more than double, and in constant returns to scale, production increased by double. For most of the hospitals surveyed in 2013, 11 hospitals were faced with diminishing returns (58\%) and only 8 hospitals had a positive scale efficiency $(0.52 \%)$. While, in 2014 , four hospitals had positive scale return and six hospitals were faced with negative scale returns. The scale efficiency changed over the past two years, which suggested that 8 hospitals had positive changes $(42 \%)$ and their scale efficiency grades increased. Five hospitals had no change (26\%) and the rest of the hospitals had negative changes (32\%). The mean scale efficiency grade of hospitals for the two years was equal to 0.956 . 
Table 5. Ranking health centers and hospitals affiliated to Tabriz University of Medical Sciences based on managerial efficiency (VRSTE) using data envelopment analysis model based on input

\begin{tabular}{|c|c|c|c|c|}
\hline Number of hospital & The year 2014 & The 2014year & Efficiency changes & Mean \\
\hline 1 & 1 & 1 & 0 & 1 \\
\hline 2 & 1 & 1 & 0 & 1 \\
\hline 3 & 0.608 & 0.663 & -0.055 & 0.6355 \\
\hline 4 & 1 & 0.840 & 0.16 & 0.92 \\
\hline 5 & 0.489 & 0.559 & -0.07 & 0.524 \\
\hline 6 & 0.836 & 1 & -0.164 & 0.918 \\
\hline 7 & 1 & 1 & 0 & 1 \\
\hline 8 & 0.726 & 0.788 & -0.062 & 0.757 \\
\hline 9 & 1 & 1 & 0 & 1 \\
\hline 10 & 0.528 & 1 & -0.472 & 0.764 \\
\hline 11 & 0.784 & 0.896 & -0.112 & 0.84 \\
\hline 12 & 0.385 & 0.418 & -0.033 & 0.4015 \\
\hline 13 & 1 & 1 & 0 & 1 \\
\hline 14 & 0.627 & 0.582 & 0.045 & 0.6045 \\
\hline 15 & 1 & 1 & 0 & 1 \\
\hline 16 & 0.948 & 0.947 & 0.001 & 0.9475 \\
\hline 17 & 1 & 1 & 0 & 1 \\
\hline 18 & 0.942 & 0.962 & -0.02 & 0.952 \\
\hline 19 & 1 & 1 & 0 & 1 \\
\hline
\end{tabular}

Table 5 presents the managerial efficiency of hospitals studied. In 2013, nine hospitals had efficiency of 1 (47\%). But in 2014, 10 hospitals had efficiency of $1(53 \%)$. Also, 8 hospitals had no changes in the managerial efficiency $(42 \%)$. Eight hospitals faced negative changes $(42 \%)$ and 3 hospitals $(16 \%)$ had positive changes. The mean of the overall managerial efficiency grade in 19 hospitals investigated was equal to 0.856 .

Table 6. Output and input surplus in hospitals on the basis of inputs.

\begin{tabular}{|c|c|c|c|c|c|c|c|c|c|c|c|c|}
\hline \multirow[t]{3}{*}{ Hospital } & \multicolumn{4}{|c|}{ Output } & \multicolumn{8}{|l|}{ Input } \\
\hline & \multirow{2}{*}{$\begin{array}{l}\text { Day } \\
\text { bed } \\
2013\end{array}$} & \multirow{2}{*}{$\begin{array}{l}\text { occupied } \\
2014\end{array}$} & \multicolumn{2}{|c|}{$\begin{array}{l}\text { Outpatient } \\
\text { admission }\end{array}$} & \multicolumn{2}{|c|}{$\begin{array}{l}\text { Specialist } \\
\text { physicians }\end{array}$} & \multicolumn{2}{|c|}{$\begin{array}{l}\text { General } \\
\text { physicians }\end{array}$} & \multicolumn{2}{|c|}{ Total staff } & \multicolumn{2}{|c|}{$\begin{array}{l}\text { Number of active } \\
\text { beds }\end{array}$} \\
\hline & & & 2013 & 2014 & 2013 & 2014 & 2013 & 2014 & 2013 & 2014 & 2013 & 2014 \\
\hline 1 & 0.000 & 9.393 & 0.000 & 628.677 & 0.000 & 0.000 & 0.320 & 0.000 & 0.000 & 0.000 & 0.000 & 0.000 \\
\hline 2 & 0.000 & 0.000 & 0.000 & 0.000 & 0.000 & 0.000 & 0.000 & 0.000 & 0.000 & 3.185 & 0.000 & 0.000 \\
\hline 3 & 0.000 & 17.409 & 302.7 & 0.000 & 0.000 & 0.000 & 2.626 & 2.719 & 0.000 & 0.000 & 0.000 & 106.095 \\
\hline 4 & 0.000 & 0.000 & 0.000 & 0.000 & 0.000 & 0.000 & 0.000 & 2.216 & 0.000 & 0.000 & 0.000 & 68.810 \\
\hline 5 & 0.000 & 2.636 & 0.000 & 0.000 & 0.000 & 0.000 & 0.000 & 0.000 & 0.000 & 0.000 & 21.534 & 284.913 \\
\hline 6 & 0.000 & 0.000 & 0.000 & 0.000 & 24.734 & 0.000 & 0.000 & 0.000 & 0.000 & 0.000 & 0.000 & 0.000 \\
\hline 7 & 0.000 & 0.000 & 0.000 & 0.000 & 0.000 & 0.000 & 0.000 & 0.000 & 0.000 & 0.000 & 12.648 & 0.000 \\
\hline 8 & 0.000 & 0.000 & 11555.1 & 39298.868 & 0.000 & 0.000 & 0.000 & 0.348 & 41.897 & 0.000 & 37.748 & 6.501 \\
\hline 9 & 0.000 & 0.000 & 0.000 & 0.000 & 0.000 & 0.000 & 0.000 & 0.000 & 0.000 & 19.674 & 40.006 & 0.000 \\
\hline 10 & 0.000 & 0.000 & 0.000 & 0.000 & 8.463 & 0.000 & 0.000 & 0.000 & 0.000 & 0.000 & 0.000 & 0.000 \\
\hline
\end{tabular}




\begin{tabular}{llllllllllllll}
\hline 11 & 0.000 & 0.000 & 1552.5 & 13659.284 & 0.449 & 0.000 & 1.258 & 0.000 & 6.493 & 0.000 & 5.708 & 24.183 \\
12 & 13.891 & 0.000 & 0.000 & 0.000 & 3.653 & 1.670 & 0.000 & 0.000 & 0.000 & 11.349 & 0.000 & 33.669 \\
13 & 0.000 & 0.000 & 0.000 & 0.000 & 0.000 & 0.000 & 0.000 & 0.000 & 0.000 & 0.000 & 46.090 & 0.000 \\
14 & 1.890 & 0.000 & 0.000 & 0.000 & 0.000 & 39.115 & 0.355 & 0.000 & 52.296 & 0.000 & 238.243 & 10.141 \\
15 & 0.000 & 0.000 & 0.000 & 20906.533 & 0.000 & 0.000 & 0.000 & 0.000 & 0.000 & 70.133 & 0.000 & 0.000 \\
16 & 13.379 & 0.000 & 0.000 & 0.000 & 1.819 & 2.667 & 1.298 & 0.006 & 18.579 & 65.839 & 92.432 & 0.000 \\
17 & 0.000 & 0.000 & 0.000 & 0.000 & 0.000 & 0.000 & 0.000 & 0.000 & 0.000 & 26.750 & 0.000 & 0.000 \\
18 & 0.000 & 0.000 & 0.000 & 0.000 & 35.397 & 0.000 & 0.000 & 0.000 & 0.000 & 0.000 & 0.000 & 0.000 \\
19 & 0.000 & 0.000 & 0.000 & 0.000 & 0.000 & 0.000 & 0.000 & 0.000 & 0.000 & 0.000 & 0.000 & 0.000 \\
Mean & 1.53 & 1.54 & 7.6 & 3921 & 4 & 2.2 & 0.308 & 0.27 & 6.27 & 10.46 & 26 & 28 \\
\hline $\begin{array}{l}\text { Mean of two } \\
\text { years }\end{array}$ & 1.535 & & 2313.5 & & 3.1 & & 0.29 & & 8.31 & & 27 & \\
\hline
\end{tabular}

Table 6 presents the outputs and inputs surplus in hospitals studied in the level of considered technical efficiency. This shows how much the hospitals under study have had extra output and input, in order to achieve the current efficiency. For example, this table indicates that since hospital 1 can stay in efficiency grade 1 , it can decrease the number of outpatient reception by $9.3 \%$. However, these hospitals lacked inputs surplus to achieve maximum efficiency grade. Hospital 18, in order to stay in the efficiency of 0.940116 , was able to reduce 35 specialist physicians. Number Zero implied that there was no additional input and output. The results indicated that the average of output surplus of occupied day beds and outpatient reception was, respectively 1.535 and 2313.5. Also, the average of input surplus of specialist's physicians, general practitioners, employees and the number of active beds was, respectively $3.1,0.29,8.31$ and 27 .

\section{Discussion}

In evaluating the activities and performance of hospitals, the main motivation for application of scientific and practical methods was the efficient use of existing physical, technological and human resources. One of the practical and appropriate tools in this field was the determination of the efficiency of these centers. In addition, since hospitals carry out their activities in an environment where there are many variables which are not in the control of the management, therefore in this research, DEA was used to assess the efficiency. In this research, technical, scale and managerial efficiency of hospitals in Tabriz city was estimated. Given that this study can help for the better management of resources and reduce costs, it goes beyond a mere study and can be used as a tool for policy making. This assessment of hospital performance enables hospitals to identify the optimal use of hospitals and their potentials, and allows inefficient hospitals to compare their performance with equal but efficient hospitals and also specify their enhanced capacity.

A comparison of the types of efficiency over the 7-year of study was done using the DEA method.

\subsection{Technical Efficiency}

Findings related to technical efficiency showed that the average technical efficiency for hospitals in Tabriz city using DEA was 817/0. A study of the training hospital of Tehran Medical Sciences University showed that only $20 \%$ of (3 hospitals) (Farzianpour et al., 2013) and 75/43\% of training health centers of Iran University of Medical Sciences (7 hospitals) had perfect efficiency (Shahhoseini et al., 2011). In this study, in 2013, six hospitals had efficiency grade 1 (31\%). In 2014, 7 hospitals had complete efficiency (36.84\%). The average of hospitals in Tabriz had complete efficiency during two years which was equal to 33.92. Among the 19 hospitals surveyed, 12 hospitals faced downward changes in efficiency over two years (64\%), 5 hospitals (26\%) had no change in the grade of technical efficiency over two years. Two (2) hospitals had positive changes in two years (10\%). Finally, in the present study, reference hospitals (hospital that is determined by software as being a model for other hospitals virtually) represented hospitals that had positive changes or no change at all, while hospitals with negative changes had at least one non reference hospital. Eight hospitals (42\%) did not have anyreference hospital while the remaining had at least one hospital as the reference hospital (58\%). (Table 3)

In this study, the efficiency of training and non-training hospitals in Ahvaz between years 85 to 89, using data envelopment analysis through descriptive- analytical techniques, was evaluated. Inputs included the number of physicians, nurses, active beds and outputs included day occupied beds, number of operations, the number of 
outpatients, the average number of patients admitted and average of patient stay. The data were collected through standardized checklists prepared by the Ministry of Health and Medical Education, and efficiency of hospitals was calculated using the WIN DEAP software. Then, the difference in hospital efficiency was examined using t-test and SPSS software. The average technical efficiency of hospitals studied was calculated as $740 / 0$. The average technical efficiency of non-training hospitals was obtained as 873 , training hospitals was 557 and their difference was significant (Amin et al., 2014).

In this regard, Masiye (2007) in Zambia in his study on the technical efficiency, reported the number of sample efficient hospitals as 40 and $47 \%$, respectively (Masiye, 2007).

\subsection{Scale Efficiency}

The findings of this study showed that in 2013, the efficiency grade of six hospitals was $1(31 \%)$. But in 2014, eight hospitals had scale efficiency grade of $1(42 \%)$. The next thing was related to the scale return indicator (Returns to scale is related to manner of changes according to identical and appropriate changes of all production factors). In increasing returns to scale, with the doubling of production factors, production was more than double. In diminishing returns to scale, production was less than double and in constant returns to scale, production was doubled. In 2013, in most of the hospitals surveyed, 11 hospitals were faced with diminishing returns (58\%) and only 8 hospitals had positive scale efficiency $(0.52 . \%)$. However, in 2014 four hospitals had positive scale efficiency $(21 \%)$ and six hospitals had negative scale efficiency $(31 \%)$. The changes in scale efficiency over the past two years suggested that 8 hospitals had positive changes $(42 \%)$ and their scale efficiency grade increased. Five hospitals had no change (26\%) and the remaining had negative changes (32\%). The mean scale efficiency of hospitals over two years was equal to 0.956 .

Farzianpour et al. in their research showed that $25 / 31 \%$ of hospitals studied during 3 years of the study had full grade in scale efficiency. The average of this type of efficiency in this study was obtained as $939 / 0$ and its average within 3 years of the study was $921 / 0,944 / 0$ and $938 / 0$, respectively which represented a sinusoidal trend of this type of efficiency in the hospital studied (Farzianpour et al.,2012,2013,).

Freire estimated the scale efficiency in 360 hospitals in America as 893/0 (Freire et al., 1990) and Byrns in 123 hospitals of the study country estimated this type of efficiency as 940/0 (Byrns, 1992). Also, Valdmanis obtained a range of this efficiency in 41 hospitals in the United Statesbetween (1 and 0/790) (Valdmanis, 1990).

The range of this efficiency in 55 hospitals in America was estimated tobe between1 and 51/0) by Maindiratt. However, in this study the average of scale efficiency was estimated to be more than that obtained in all these studies (956/0) and its range is between 1 and 73/0) (Maindiratt, 1990).

\subsection{Net Technical Efficiency (Managerial)}

The findings of the study indicated that in 2013, nine hospitals had efficiency grade $1(47 \%)$. But in 2014, 10 hospitals had efficiency grade 1 (53\%). Also, 8 hospitals had no changes in managerial efficiency (42\%). Eight (8) hospitals faced negative changes $(42 \%)$ and 3 hospitals $(16 \%)$ had positive changes. The mean of the overall managerial efficiency of the 19 hospitals surveyed is equal to 0.856 . In the research conducted by Farzianpour et al., the findings of pure technical efficiency (management) assessment showed that generally, the average of this efficiency during the period under study almost had an upward trend, that is, during the years of study it was estimated, respectively as $0 / 954,1,0 / 979$ (with range $954 / 0$ to 1 ), with an overall mean of 982/0 whichis an indicator of good management and the correct combination of production factors which provided the enhancement of this efficiency. Over the five years of study, $5 / 62 \%$ of hospitals obtained full efficiency in this regard (Farzianpour et al., 2012).

\subsection{Input and Output Surplus}

The results showed the amount of input and output surplus required by the hospitals under study to achieve the current efficiency levels. For example, Tables 4 to 6 indicate that for hospital 1 to stay in efficiency grade 1, it had to decrease the outpatient admissions by 9.3 percent or decrease the number of outpatient admission by 628.67 percent. However, this hospital lacked the input surplus to achieve maximum efficiency grade. Also, hospital number 18, in trying to stayin efficiency 0.940116 had to reduce its 35 specialist physicians. Zero implies lack of input and output surplus. The results of the study indicated that the average output surplus of day occupied bed and outpatient reception was, respectively 1.535 and 2313.5. Also, the average surplus of specialists' physicians, general physicians, total number of employees and the number of active beds were, respectively $3.1,0.29,8.31$ and 27.

In a study entitled technical efficiency of hospitals of Guilan University of Medical Sciences,the results showed 
that the hospitals under study, regarding bed, doctors, nurses and other staff, had surplus of, respectively 92.67 , 58.18, 125.82 and 81.17(Mohebifar et al.,2010).In other study to determine the technical efficiency of hospitals affiliated to Tehran University of Medical Sciences, using data envelopment analysis (DEA) years from 1996 to 2006 the results showed that in thehospitals under study, the inputs of beds, doctors, nurses and other staff had surplus unit on an average of 2, 0.76, 5.1 and 1 (Tofighi et al.,2002).

\section{Conclusion}

The overall efficiency of the hospitals was not satisfactory. Managers should make more efforts to improve the hospitals efficiency and plan towards its achievement. Since the measurement of efficiency provides a criteria for comparing the benefits from the existing resources, a comparison with the standard criteria or indicators in assessing the performance of hospitals' university officials can usean efficiency ranking of nine for budgeting and financing the hospitals.

There are many indicators to measure hospital performance in scientific literature. The use of these indicators to monitor the performance of hospitals is extremely important, as it includes benefits like determining important organizational objectives for policy makers, guidance of programs for future services, and management of existing resources. The use of individual performance indicators may lead to mistakes in the conclusions regarding total performance of the hospital. For example, high percentage of occupied beds can be a result of high average length of stay, which is the result of efficient use of resources for patients in need, and can be due to unnecessary hospitalization and inefficient use of resources.

Given the high importance of hospitals in providing health care services together with their high impact on the efficiency of the health management system, the use of data envelopment analysis, with the possibility of comparison, ranking, and modeling can be an important step in the continuous improvement of hospitals performance, especially the health sector of the country.

Finally, given the excess capacity in the production factors of the hospitals under study, it seems that a decrease of these factors of production should be based on a comprehensive planning, with a consideration of all aspects.

\section{Limitations of the Study}

- Lack of classified and identical information in the studied hospitals which made data collection difficult.

- Lack of cooperation of some hospitals which resulted in their removal from the research population.

- Hospitals staff not being familiar with the research subject.

\section{Acknowledgements}

This research was supported by Tehran University of Medical Sciences \& health Services grant 28516, 2015/01/27 and we appreciate the kind collaboration of Tabriz University of Medical Sciences, and also all the Managers in Tabriz Province for the careful completion of our questionnaires.

\section{Competing Interests Statement}

The authors declare that there is no conflict of interests regarding the publication of this paper.

\section{References}

Abbasi, S., Tavakoli, N., \& Moslehi, M. (2012). Readiness of Hospitals with Quality Management Systems Based on Joint Commission on Accreditation Standards. Health Information Management, 9, 1-11.

Afzali, H. H. A., Moss, J. R., \& Mahmood, M. A. (2009). A conceptual framework for selecting the most appropriate variables for measuring hospital efficiency with a focus on Iranian public hospitals. Health Serv. Manage. Res., 22, 81-91. http://dx.doi.org/10.1258/hsmr.2008.008020

Amin Torabipour, A., Najarzadeh, M., Arab, M., Farzianpour, F., \& Ghasemzadeh, R. (2014). Hospitals Productivity Measurement Using Data Envelopment Analysis Technique. Iranian Journal of Public Health 43(11), 1576-1581.

Bakhateiyari, M., Farzianpour, F., Arab, M., Rahimi Foroushani, A., et al. (2015). Evaluating the Performance of Managers of Tehran University of Medical Sciences' Obstetrics and Gynecology Hospitals from the Viewpoint of Personnel. Journal of Service Science and Management, 8, 209-215. http://dx.doi.org/10.4236/jssm.2015.82023

Banker, R. D., \& Morey, R. C. (1986). Efficiency analysis for exogenously fixed inputs and outputs. Operations Res., 34, 513-513. http://dx.doi.org/10.1287/opre.34.4.513 
Barnum, D. T., Walton, S. M., Shields, K. L., \& Schumock, G. T. (2009). Measuring hospital efficiency with data envelopment analysis: NonsubstitutableVs. Substitutable Inputs and outputs. J. Med. Syst, 35, 1393-1401. PMID: 20703515. http://dx.doi.org/10.1007/s10916-009-9416-0

Byrnes, P. (1994). Analyzing technical and Allocative Efficiency of Hospitals, In A. Charnes, W. Cooper, \& A. Lewin (Eds.), DEA Theory, Methodology and Applications (Kluwer, Boston, 1994). http://dx.doi.org/10.1007/978-94-011-0637-5_7

Charnes, A., Cooper, W. W., \& Rhodes, E. (1978). Measuring the efficiency of decision making units. Eur. J. Oper. Res., 2, 429-444. http://dx.doi.org/10.1016/0377- 2217(78)90138-8

Cook, W. D., \& Zhu, J. (2008). Data Envelopment Analysis: Modeling Operational Processes and Measuring Productivity (1st ed., pp. 262). CreateSpace, USA

Farzianpour, F., Aghababa, S., Delgoshaei, B., \& Haghgoo, M. (2011). Performance Evaluation a Teaching Hospital Affiliated to Tehran University of Medical Sciences Based on Baldrige Excellence Model. American Journal of Economics and Business Administration, 3, 277-281. http://dx.doi.org/10.3844/ajebasp.2011.272.276

Farzianpour, F., Arab, M., Amoozagar, S., Fouroshani, A. R., Rashidian, A., Moghadam, M. N., \& Hosseini, S. (2011). Evaluation of International Standards of Quality Improvement and Patient Safety (QPS) in Hospitals of Tehran University of Medical Sciences (TUMS) from the Managers' Point of View. World Applied Sciences Journal, 15, 647-653.

Farzianpour, F, Geray, S., Fouroshani, A. R., Arab, M., \& Hosseini, S. H. (2013). Evaluation of International Standards "Access to Care and Continuity of Care (ACC). Hospital of Tehran University of Medical Sciences Heath, 5, 2110-2115.

Farzianpour, F., Askari, R., Torabipoor Hamedani, A., Khorshidi G. H., \& Amirifar, S. (2011). Accreditation of Emergency Department at a Teaching Hospital in Tehran University of Medical Sciences. American Journal of Economics and Business Administration, 3, 498-505. http://dx.doi.org/10.3844/ajebasp.2011.498.505

Farzianpour, F., Kalantari, E., Fouroshani, A. R., \& Alirezaei, S. (2014). Assessment of Patient (AOP) Standards in Teaching Hospitals in Iran. Pensee Journal, 76, 119-124.

Farzianpour, F., Fouroshani, A. R., \& Kalantari, E. (2014). Evaluation of Care of Patient (COP) Standards in Selected Hospitals of Tehran University of Medical Sciences. Pensee Journal, 76, 179-186.

Farzianpour, F., Hosseini, S., Amali, T., Hosseini, S. H., \& Hosseini, S. S. H. (2012). The Evaluation of Relative Efficiency of Teaching Hospitals. American Journal of Applied Sciences, 9(3), 392-398. http://dx.doi.org/10.3844/ajassp.2012.392.398

Ferrier, G. D., \& Lovell, C. A. K. (1990). Measuring cost efficiency in banking econometrics and linear $\begin{array}{lllll}\text { Programming evidence. Journal of econometrics, } & 46, & 229-45 .\end{array}$ http://dx.doi.org/10.1016/0304-4076(90)90057-Z

Gagliardi, A. R., Majewski, C., Victor, J. C. et al. (2010). Quality Improvement Capacity: A Survey of Hospital Quality Managers. Quality and Safety in Health Care, 19, 27-30. http://dx.doi.org/10.1136/qshc.2008.029967

Maindiratta, A., Largest. (1990). Size-efficient scale and size efficiencies of decision-making units in data $\begin{array}{lllll}\text { envelopment analysis. Journal of } & \text { Econometrics, } & 46(1-2), & \text { 57-72. }\end{array}$ http://dx.doi.org/10.1016/0304-4076(90)90047-W

Masiye, F. (2007). Investigation Health System Performance: An Application of Data Envelopment Analysis to Zambian Hospitals. BMC Health Services Research, 7, 58. http://dx.doi.org/10.1186/1472-6963-7-58

Mohebifar, R., Goudarzi, G. H., \& Rahimi, H. (2010). Technical efficiency of hospitals under Guilan University of Medical Sciences. Journal of Guilan University of Medical Sciences, 22(3), 11-19 (Persian).

Mohammad Pour, A., Mehdi Pour, Y., \& Rahday, K. A. (2008). Comparison of Patient and Family Education Standards of the Iranian Ministry of Health, Joint Commission on Accreditation of Health Care Centers of America. Health Information Management, 6, 113-122.

Nikoukar, S., Ketabi, S., \& Moazam, E. (2011). A Combined Model of Data Envelopment Analysis (DEA) and Analytical Hierarchy Process (AHP) in ranking of hospital managers. Health Information Management, 7(3), 601-611. 
Safi Arian, R., Shahhoseini, R. (2010). Assessment of technical efficiency of hospitals under Hamadan University of Medical Sciences on performance indicators and data envelopment analysis model in 2010. Pajouhan Journal, 11(2), 27-34. (Persian)

Shahhoseini, R., Tofighi, S., Jaafaripooyan, E., \& Safiaryan, R. (2011). Efficiency measurement In developing countries: Application of data envelopment analysis for Iranian hospitals. Health Services Manage. Res., 24, 75-80. http://dx.doi.org/10.1258/hsmr.2010.010017

Tlotlego, N., Justice Nonvignon, J., Sambo, G., Asbu, L., \& Kirigia, J. M. (2010). Assessment of productivity of hospitals in Botswana: a DEA application. Int Arch Med., 3, 27. http://dx.doi.org/10.1186/1755-7682-3-27

Tofighi, S., Poorreza, A., \& Manochehri-Moghadam, Z. (2002). Provide a suitable model for the design of the hospital management information system based on processes and participation of hospital managers. Tehran; Proceedings First National Congress on Resource Management in Hospitals. [Persian]

Valdmanis, V., \& Sensivity. (1992). Analysis for DEA Model -an empirical example using public vs. NFP hospital. Journal of Public Economics, 48(2), 185-205. http://dx.doi.org/10.1016/0047-2727(92)90026-C

\section{Copyrights}

Copyright for this article is retained by the author(s), with first publication rights granted to the journal.

This is an open-access article distributed under the terms and conditions of the Creative Commons Attribution license (http://creativecommons.org/licenses/by/4.0/). 